\title{
Erratum to: Difficult peritonitis cases in children undergoing chronic peritoneal dialysis: relapsing, repeat, recurrent and zoonotic episodes
}

\author{
Sevcan A. Bakkaloglu • Bradley A. Warady
}

Published online: 7 November 2014

(C) IPNA 2014

\section{Erratum to: Pediatr Nephrol}

DOI 10.1007/s00467-014-2952-y

An error has occurred in Table 2.

The correct Table 2 is:

Table 2 Indications for catheter removal for peritoneal dialysisassociated infections. (Adapted from [12], used with permission).

\begin{tabular}{lll}
\hline Approach to catheter & Indication & Reinsertion \\
\hline Definite removal & Refractory bacterial peritonitis & After 2-3 weeks \\
& Fungal peritonitis & After 2-3 weeks or more \\
& ESI/TI in conjunction with peritonitis & After 2-3 weeks \\
& with the same organism (mainly & \\
& Staphylococcus aureus and & \\
& Pseudomonas aeruginosa; except & \\
coagulase-negative staphylococci) & \\
Simultaneous removal & Repeatedly relapsing or refractory ESI/TI & \\
and replacement & (including P. aeruginosa) & \\
Relative indication & Relapsing peritonitis & Repeat peritonitis \\
for removal & Mycobacterial peritonitis & After 2-3 weeks \\
& Peritonitis with multiple enteric organisms & Depends on the clinical course of the \\
& because of an intra-abdominal & patient; after 2-3 weeks or more \\
& pathology or abscess; so-called & \\
& surgical peritonitis & \\
\hline
\end{tabular}

The online version of the original article can be found at http://dx.doi.org/ 10.1007/s00467-014-2952-y.

\footnotetext{
S. A. Bakkaloglu $(\bowtie)$

Department of Pediatrics, Division of Pediatric Nephrology, Gazi

University School of Medicine, Ankara, Turkey

e-mail: sevcan@gazi.edu.tr

B. A. Warady

Division of Pediatric Nephrology, Children's Mercy Hospital, University of Missouri-Kansas City School of Medicine, Kansas

City, MO, USA
} 